\title{
EL RÍO LOIRA, RÍO REAL DE FRANCIA. SEGUNDA PARTE
}

\section{THE RIVER LOIRE, FRANCE ROYAL RIVER. SECOND PART}

\author{
Guy Amaru: ANAYA \\ g.amaru@ozu.es
}

\section{CURRÍCULUM VITAE}

Francés nativo de Tahití. Es capitán de la Marina Mercante francesa. Pertenece a la sociedad francesa ANAYA compuesta de españoles en Francia y franceses amantes de la cultura española.

\section{RESUMEN}

El río Loira es el más largo de Francia y el último río salvaje de Europa. Según se sitúen al norte o al sur del río Loira, la gente, las costumbres, la gastronomía, los dialectos, son diferentes. Los puentes que cruzan este río sirven para unir unas zonas con otras, pero también son un símbolo de la unidad del país galo. Pero también hay castillos de mucho renombre a lo largo de la rivera del Loira, como el Chambord. Este castillo es el más grande y famoso de todos, construido por el rey Francisco I por su afición a la caza. Pero, además, el valle del Loira es una de las regiones vitivinícolas de Francia productoras de vinos de gran calidad. Aunque también nos encontramos cuatro centrales nucleares a lo largo de su cauce. 


\title{
PALABRAS CLAVE
}

Río Loira - Francia - Castillo - Vino - Central nuclear

\begin{abstract}
The Loire is the longest in France and the last wild river in Europe. As are located north or south of the Loire, people, customs, cuisine, dialects are different. The bridges over this river used to join some other areas, but also a symbol of national unity Gallo. But there are also very famous castles along the banks of the Loire, such as Chambord. This castle is the largest and most famous of all, built by King Francis I for his love of hunting. But in addition, the Loire Valley is one of France's wine regions producing wines of great quality. Although we also found four nuclear power plants along its banks.
\end{abstract}

\section{KEY WORDS}

River Loire - France - Castle - Wine - Nuclear Power Plant

\section{ÍNDICE}

1. Los Castillos del Loira

1.1 CHAMBORD

1.2 BLOIS

1.3 AMBOISE

1.4 CHENONCEAU

2. Los vinos del Loira

2.1 Origen de la poda (en plan de broma)

2.2 Aficionados de los vinos del Loira 
3. Medioambiente y centrales nucleares

4. Cuando se enfada la Naturaleza

4.1 Grandes riadas

4.2 El hielo

5. Conclusión

TEXTO

\section{Los Castillos del Loira}

Si al Loira lo llamamos río real de Francia, se debe sobre todo a los castillos que los reyes construyeron o embellecieron en su valle, durante los siglos XV y XVI. Constituyen un legado inapreciable, que hoy día millares de turistas visitan, siendo los castillos del Loira el segundo destino turístico en Francia, después de París.

Todos estos castillos tienen características comunes, pero únicas. Ya no son las fortalezas de la Edad Media que siguen dominando en toda Europa; todavía no tienen nada que ver con los edificios clásicos del XVIII que hallamos en muchos países, y tampoco con los castillos románticos y neo-góticos que iban a construir los príncipes alemanes más tarde.

Se destacan por sus siluetas elegantes, aún con rasgos medievales, como las torres de esquina con techos puntiagudos, pero con muchas puertas y ventanas en las murallas y chimeneas preciosas en los tejados. Claramente, no son castillos para la defensa, sino residencias agradables y de ocio. Además, todos están construidos con esta piedra blanca, propia del valle del Loira, el «tuffaut». Y, sin embargo, ninguno se asemeja a otro. 
Por consiguiente, sólo vamos a citarlos todos sin describirlos en detalle, aunque nos pararemos en algunos, aquellos que verdaderamente sobresalen por sí mismos, por su historia o los eventos que en ellos sucedieron.

Todos ellos están ubicados en las riberas del Loira o muy cerca, a orillas de alguno de sus afluentes. Bajando el valle, encontramos en primer lugar los castillos de Gien y Sully; aunque no estén formalmente incluidos en el circuito tradicional, son de gran interés. Luego vienen Chambord, junto al río Cosson, Blois, en el centro de la ciudad del mismo nombre, Chaumont, Amboise, Chenonceau, haciendo puente sobre el río Cher, Luynes, Villandry, Langeais, Azay le Rideau y Ussé, a orillas del río Indre, y, finalmente, Saumur.

\subsection{CHAMBORD}

Sin ninguna duda, Chambord es el más grande, majestuoso y famoso de todos los castillos del Loira. Algunos datos: situado en un parque boscoso, cercado por un muro de $32 \mathrm{~km}$, tiene una fachada de $156 \mathrm{~m}$, una altura de $56 \mathrm{~m}, 440$ salas, 83 escaleras, 365 chimeneas...

El rey Francisco I (François Ier) mandó construirlo en este lugar de bosques inmensos por su afición a la caza. Leonardo da Vinci le inspiró los planos y la construcción empezó en 1519. Durante 30 años, 1.800 obreros trabajaron en esa obra, pero era tan gigantesca que Francisco I no pudo terminarla. No obstante, nunca faltó dinero para su edificación, anteponiéndola al pago del rescate de sus dos hijos, rehenes del emperador Carlos V (Carlos I de España), en Madrid, tras la batalla de Pavía en 1525. Finalmente, Luis XIV terminó el castillo en el siglo XVII, donde gustaba hacer numerosas y largas estancias, cazando y organizando fiestas, amenizadas con ballets y obras de teatro de Molière. 

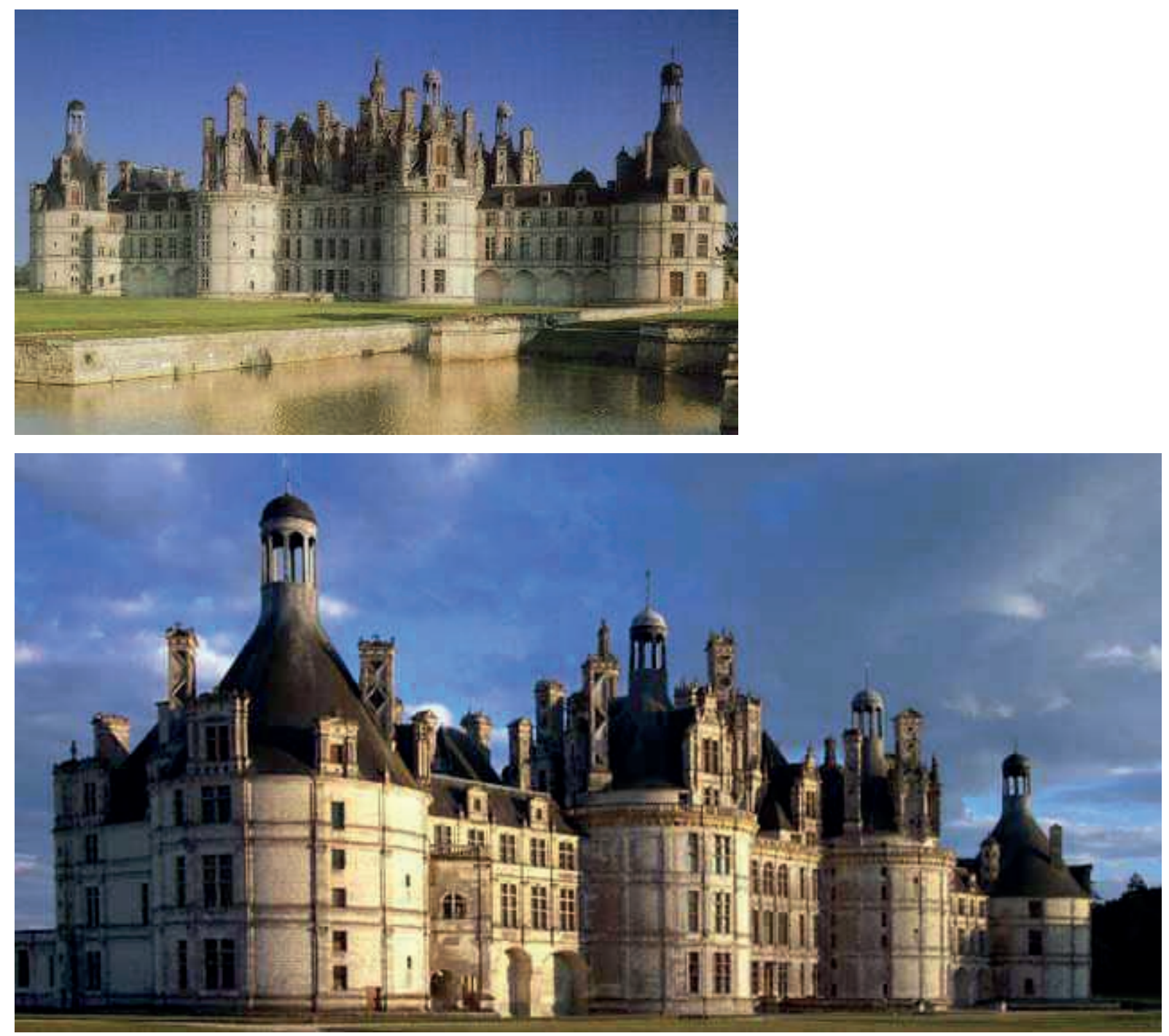

Vistas generales del Castillo de Chambord 


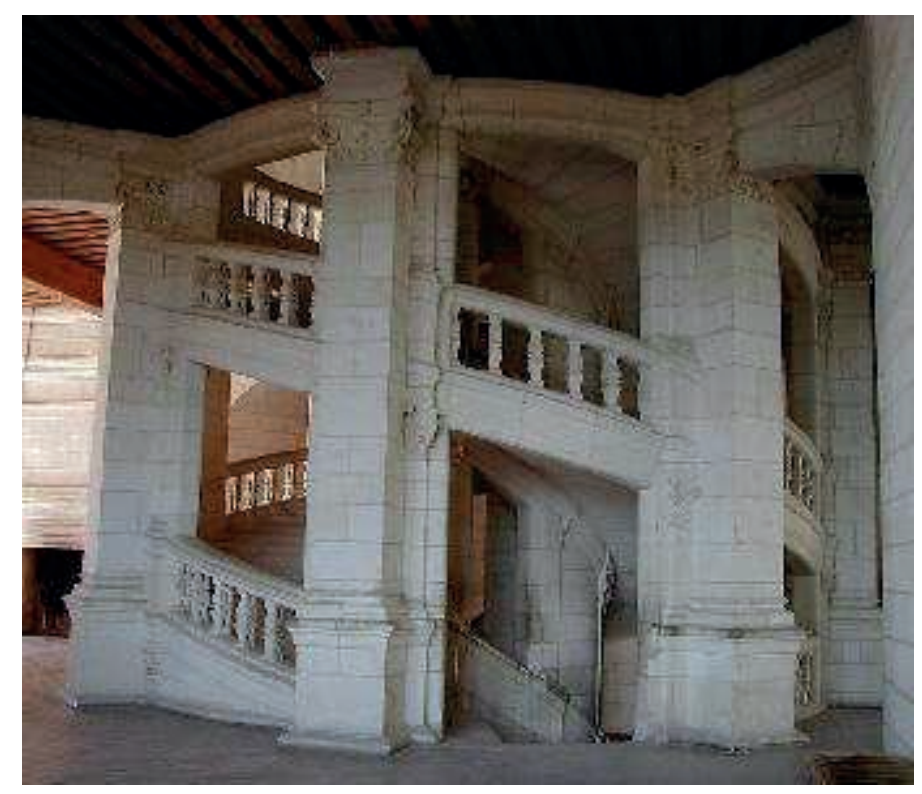

Castillo de Chambord. Escalera interior principal

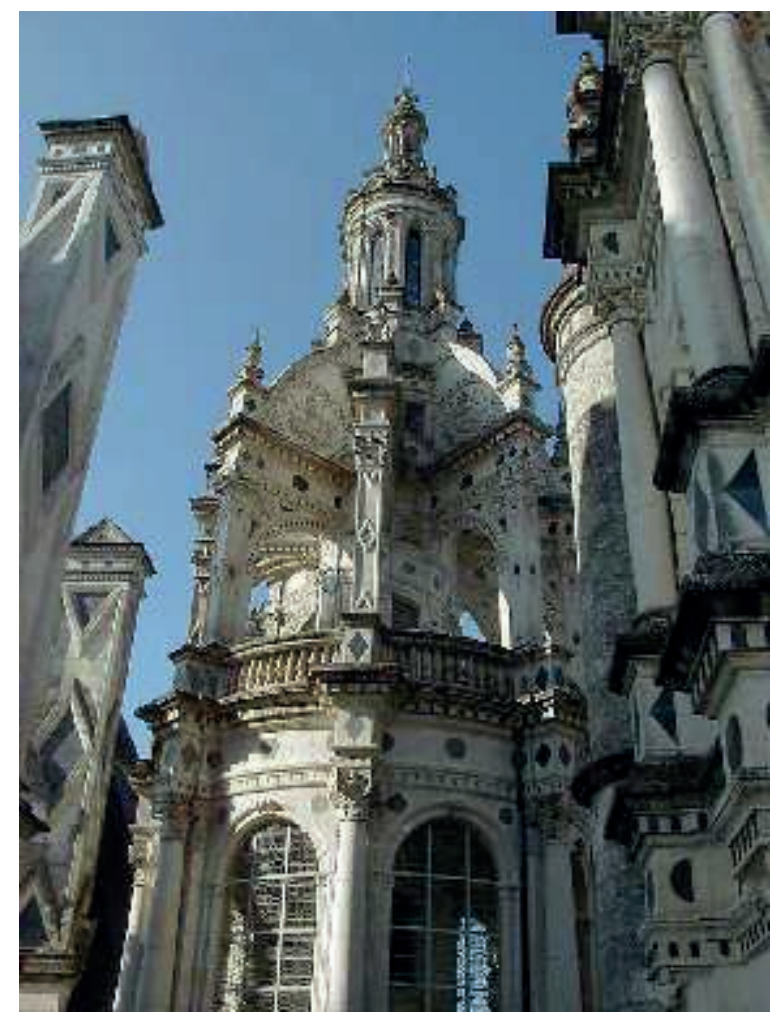

Castillo de Chambord. Detalle de una de las torres 


\subsection{BLOIS}

El castillo de Blois está construido dentro de la ciudad, en su parte alta. En él se mezclan el estilo gótico del Siglo XIII y los primeros rasgos del renacentista, traídos de Italia por el rey Luis XII, nacido entre sus muros. Fue completado por Francisco I en el Siglo XVI y, más tarde, se adjuntaron a las clásicas.

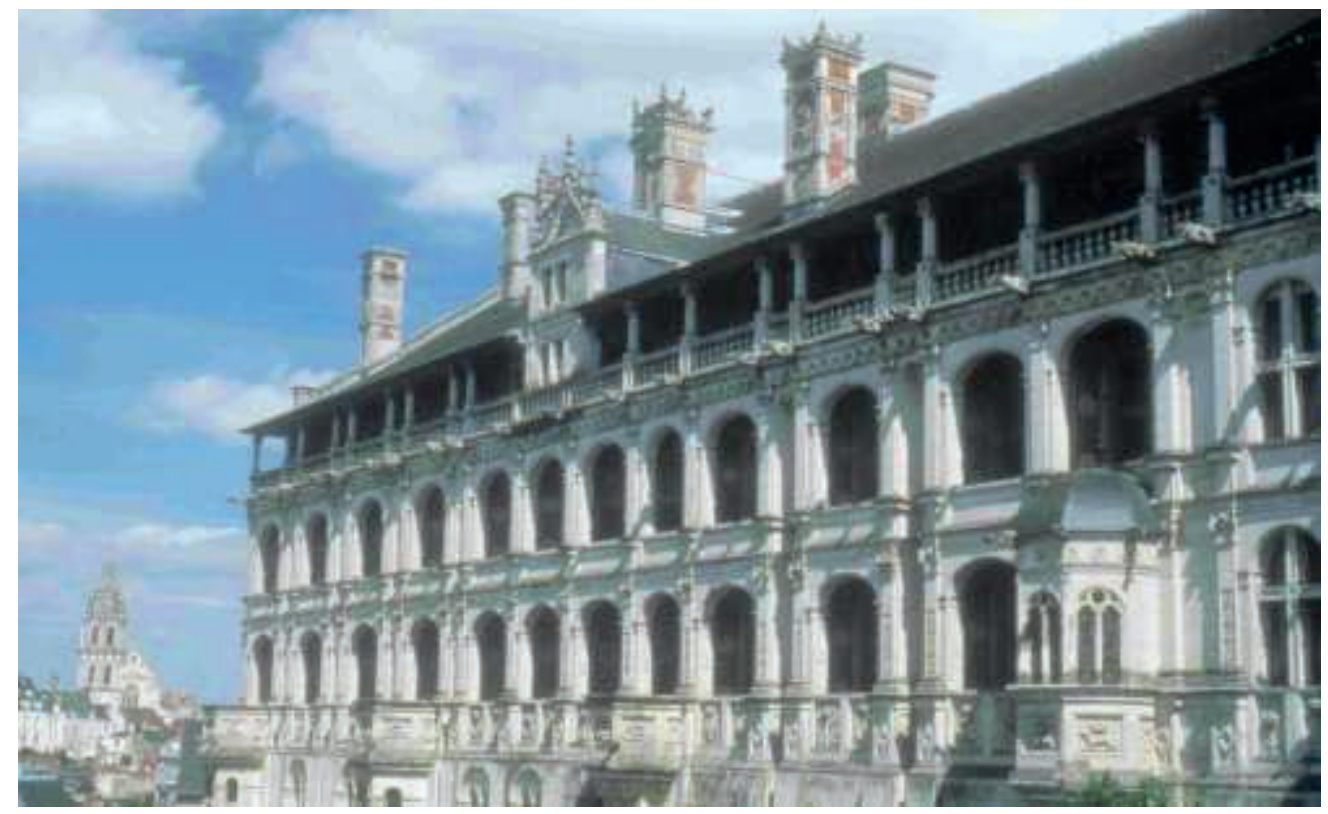

Fachada del Castillo de Blois

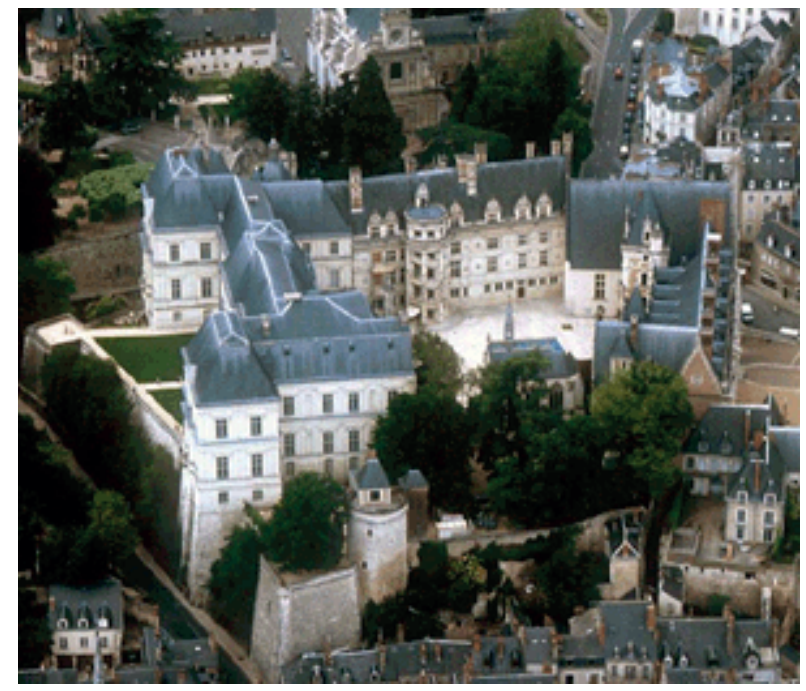

Vista aérea del Castillo de Blois 
Al ser proclamado rey en 1498, Luis XII instaló la corte en Blois, que se convirtió en capital del Reino.

El castillo fue el marco de un evento trágico y sangriento. En 1588, el Reino sufre las guerras de religión desde hacía 28 años. El rey Enrique III, sin descendiente varón, se había comprometido a dejar el trono a su primo Enrique de Navarra, que capitanea el bando protestante. El pueblo de París y el bando católico, bajo las órdenes del Duque Enrique de Guisa (hijo del Duque de Saumur - ver más adelante) y de su hermano el Cardenal de Lorena, obligan al rey a huir de la capital y a refugiarse en Chartres. Enrique III finge someterse a las condiciones de los Católicos y reconciliarse con los Guisa, nombrando a Enrique Teniente General del Reino. Aprovechando la reunión en Blois de los «Etats généraux», el 23 de diciembre de 1588, el rey convoca a Enrique de Guisa a sus aposentos del castillo, so pretexto de arreglar unos asuntos corrientes antes de Navidad. Pero nueve gentilhombres de su guardia personal se han escondido en la habitación y, al llegar el Duque, le apuñalan hasta la muerte, pese a una resistencia salvaje. El rey, al verlo tumbado, exclamó: «¡Dios!, es aún más grande muerto que vivo». ¡El Duque de Guisa medía más de dos metros!

Al día siguiente, asesinaron a su hermano, quemaron su cuerpo y le arrojaron al río. ¡Otro más! 


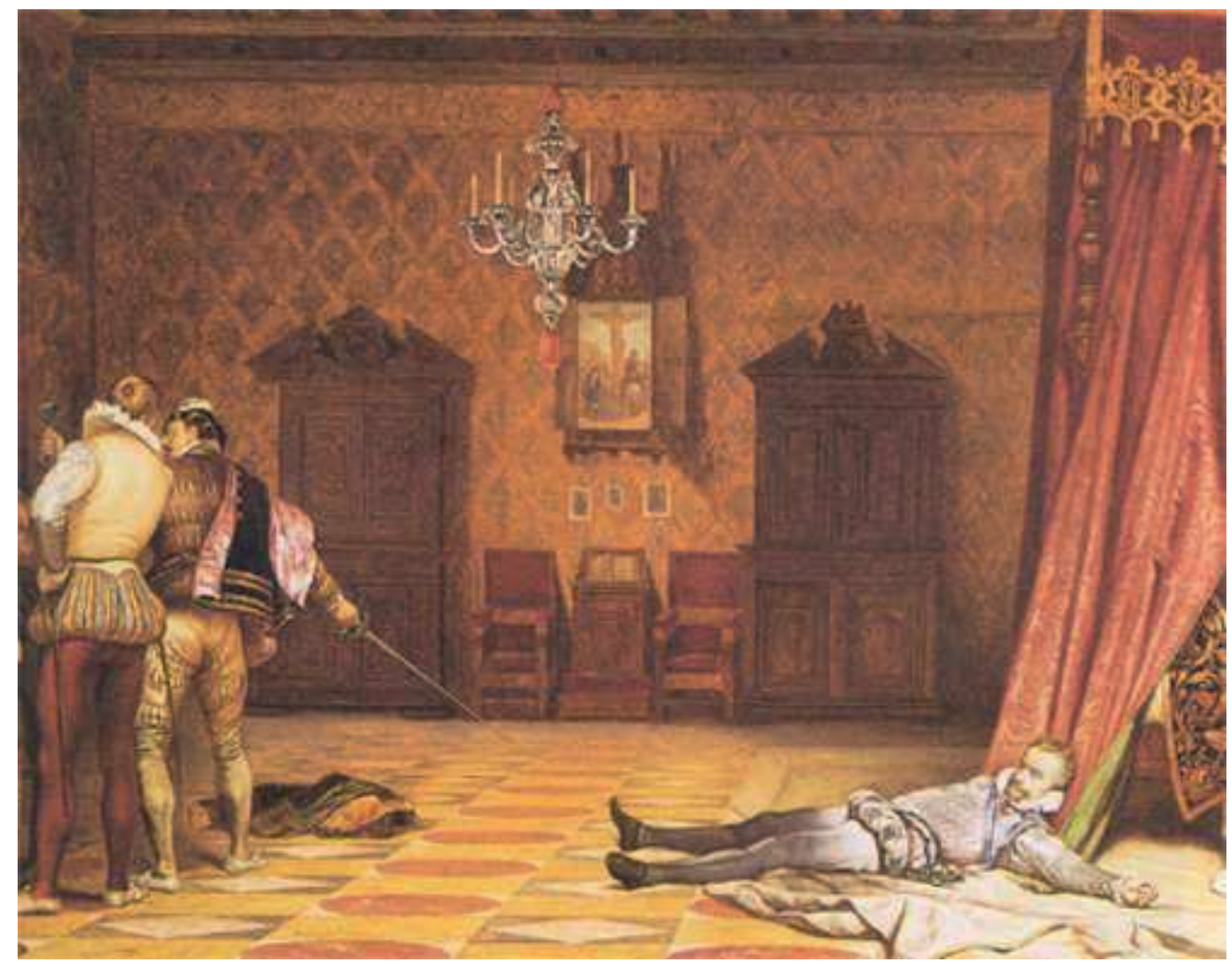

Asesinato del Duque de Guisa

\subsection{AMBOISE}

El rey Carlos VIII quiso reconstruir la antigua fortaleza medieval, edificada sobre una altura de la ribera izquierda del Loira, en estilo renacentista, según los planos de dos maestros albañiles italianos. Carlos admiraba este movimiento artístico, floreciente en Italia, y, por otra parte, estaba muy apegado al sitio donde había nacido, en 1470, y pasado su mocedad. Allí también se había casado con Ana de Bretaña en 1491. Así, el nuevo castillo, que domina majestuosamente el río y la ciudad, fue el primero de estilo renacentista de todos los que luego fueron construidos en el valle.

En abril de 1498, dirigiéndose a la sala de juego de palma del castillo, Carlos se dio un fuerte golpe en la frente contra el dintel de una puerta baja y murió unas horas después. 
Muy próximo al castillo de Amboise estaba el Manoir du Cloux, que Carlos VIII compró en 1490 para integrarlo al dominio real. Durante su reinado, Francisco I siguió introduciendo en Francia las ideas del Renacimiento italiano y, en 1515, acogió en esta casa solariega al genio de la época, Leonardo da Vinci. Éste permaneció allí los 3 últimos años de su vida, dedicándose, no a la pintura, sino a los bocetos de varios proyectos científicos, militares o de obra civil, y a reunirse con otros artistas, poetas, arquitectos..., también invitados del Rey. En este lugar, de puro estilo renacentista, Leonardo falleció en 1519.

Hoy día, el lugar se llama Le Clos Lucé y se dedica al recuerdo de Leonardo da Vinci, con una exposición permanente de modelos y bosquejos de sus invenciones, entre las cuales mencionaremos las máquinas de volar, el carro de combate, la ametralladora y los sistemas de riego y alcantarillas.

En marzo de 1560, una tropa de conjurados protestantes había planeado matar a los hermanos De Guisa (Francisco y el Cardenal de Lorena), católicos fanáticos que dominaban la política del reino, y tomar al rey, Francisco II de 16 años, como rehén. Fueron traicionados, detenidos y ejecutados inmediatamente, algunos cuerpos fueron arrojados al río, otros se expusieron colgados de un balcón del castillo. Este episodio fue el primer acto desencadenante de las guerras de religión que ensangrentaron Francia durante unos 30 años. 


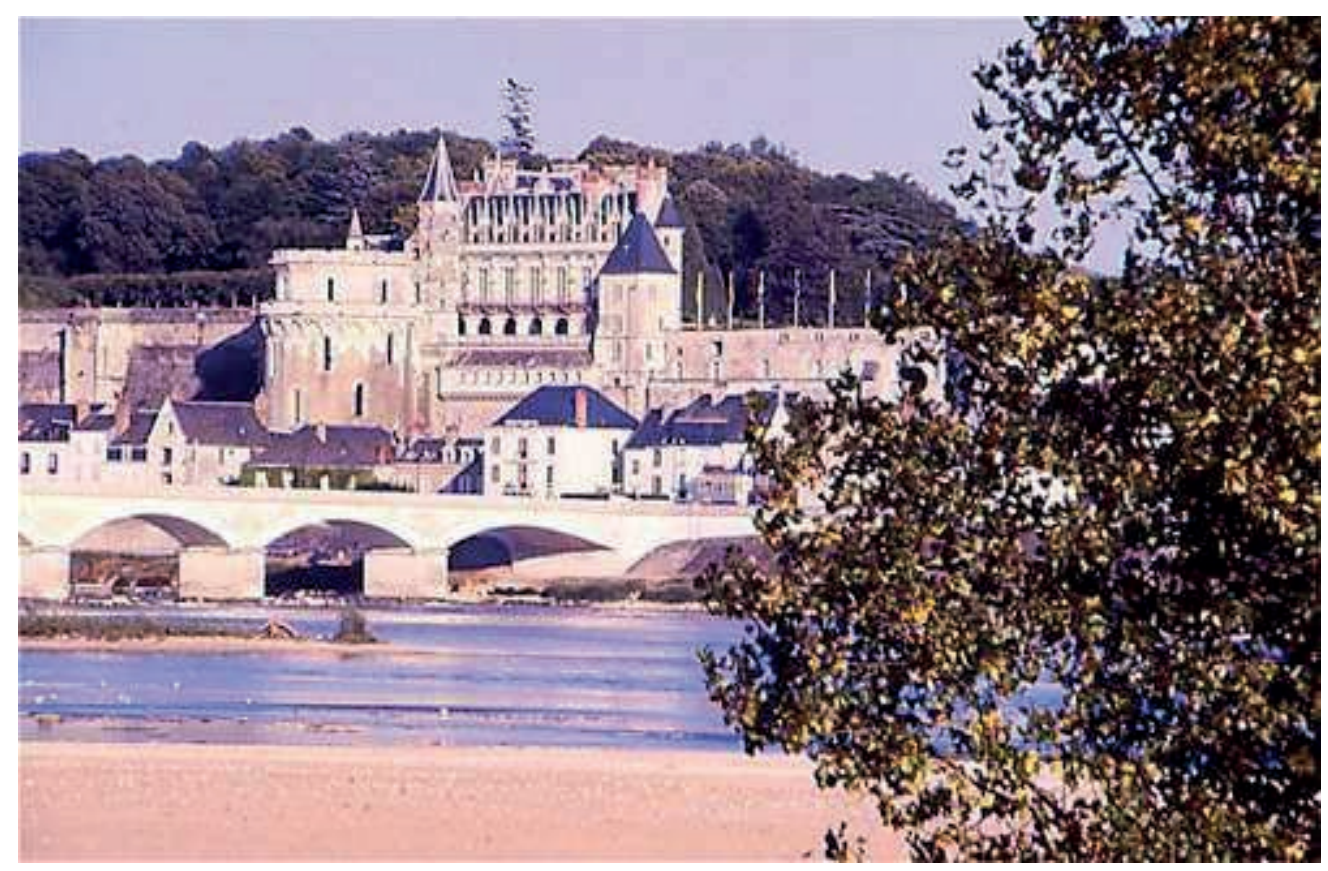

Castillo de Amboise

\subsection{CHENONCEAU}

Este castillo de larga historia es hoy día el que más visitantes atrae, después del palacio de Versalles; tal vez por su originalidad, pues está construido como si fuera un puente sobre el río Cher.

La historia de Chenonceau está marcada por dos grandes damas, que completarán su edificación y la realización de sus jardines, pero, sobre todo, que supieron izarlo a nivel de residencia real con todo el fasto y el lujo de la corte de la época.

La primera es Diana de Poitiers, tan bella a pesar de su edad, que se convirtió, en 1547, en la amante de Enrique II, hijo y heredero de Francisco I. Enrique, 20 años más joven que Diana, ofreció a ésta Chenonceau y el título de Duquesa de Valentinois. Ella se dedicó a embellecer el castillo y consiguió que el Rey, con toda la corte, se trasladara a Chenonceau, donde ofrecía bailes, juegos, torneos y cacerías para la nobleza. Al mismo tiempo, se convirtió en la mujer más influyente del reino y, por 
supuesto, en la enemiga de la Reina, Catalina de Medicis. Relegada al segundo lugar, Catalina no podía comprender lo que atraía a su marido, de 28 años, de esa mujer de 48. A tal punto estaba intrigada, que mandó abrir un agujero en un muro de su habitación. ¡Así lo comprendió! Pero, en realidad, lo que la Reina quería era echar a Diana y recuperar Chenonceau, para que volviera al dominio real y, por consiguiente, al suyo.

Y lo consiguió tras el trágico accidente en que perdió la vida el Rey Enrique II, de una lanzada, en un torneo contra Montmorency, capitán de su guardia escocesa. Catalina hará entonces de Chenonceau algo aún más bello y grande de lo hecho por su rival. Fue Catalina quien hizo construir la gran galería que atraviesa el río, cuya inauguración tuvo lugar en 1577 con una fiesta para su tercer hijo, el Rey Enrique III.

Hoy día, el castillo es propiedad de la familia Menier, los fabricantes del chocolate.

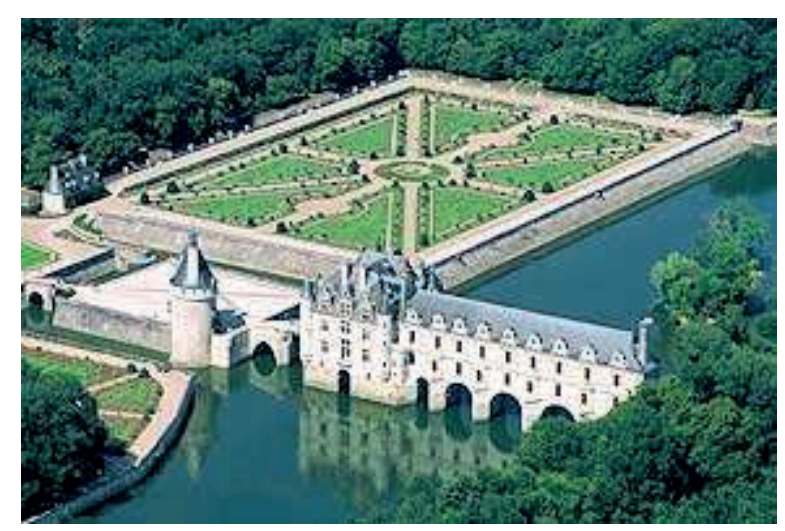

Vista aérea del Castillo de Chenonceau 


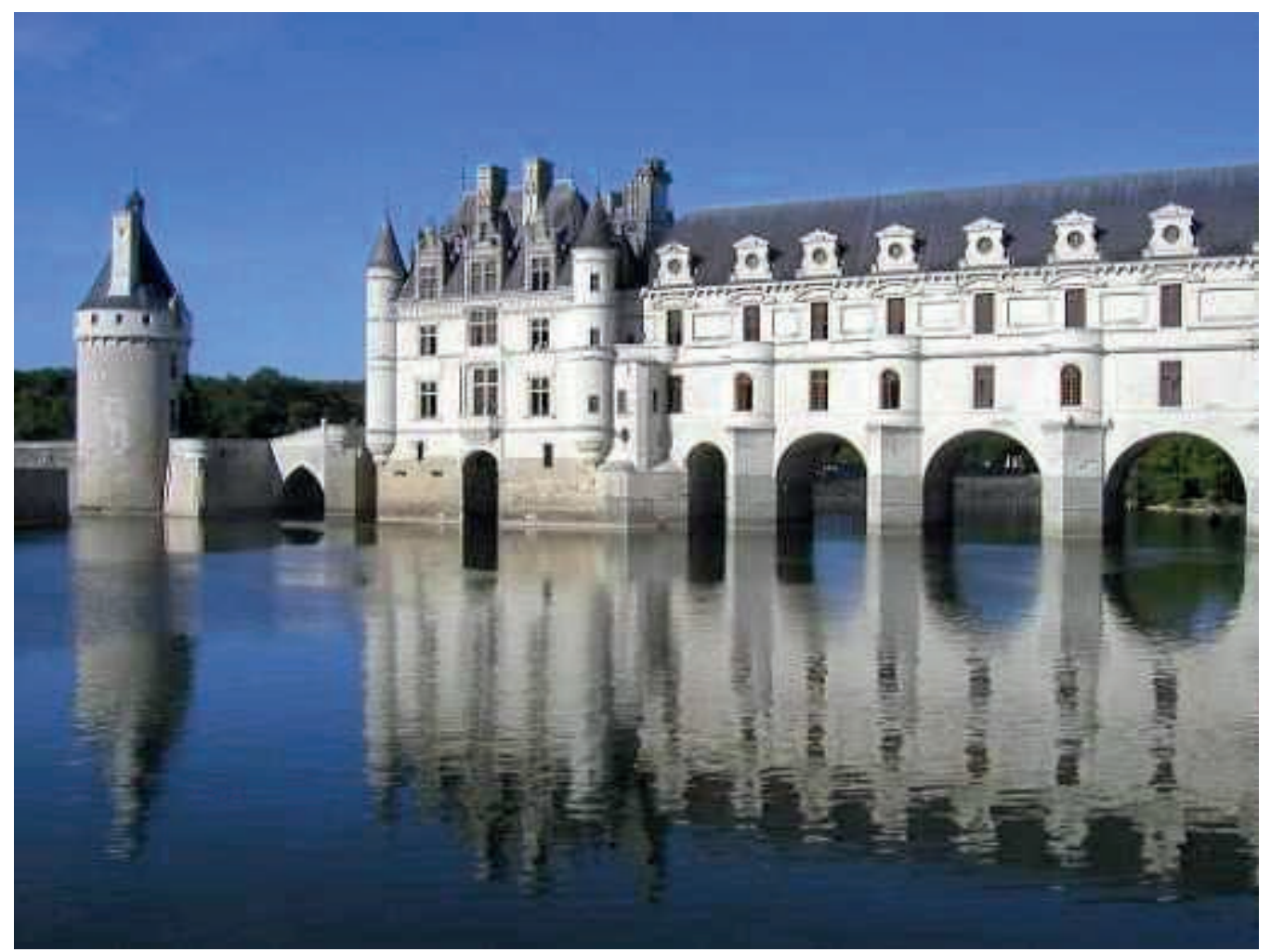

Detalle de la galería sobre el río Cher del Castillo de Chenonceau

\section{Los vinos del Loira}

El valle del Loira es una de las regiones vitivinícolas de Francia productoras de vinos de gran calidad. Las áreas cultivadas se extienden desde la desembocadura hasta Sancerre y Pouilly, muy cerca de Nevers, y se dividen en cuatro zonas: la del País de Nantes, la de Anjou, la de Touraine y la de los vinos del Centro. Los viñedos se ubican, en su mayoría, en la ribera izquierda (Sur), aprovechando un relieve de cerros y terrenos calcáreos que permiten la excavación de bodegas subterráneas de todos los tamaños.

Ya en la época galo-romana, tenemos constancia de un viñedo perteneciente a la Abadía de Micy, muy cerca de Orléans. El auge vendrá durante la Edad Media, como veremos más adelante. 
La zona de Nantes produce los blancos secos Gros Plant y sobre todo Muscadet, tan bueno con los mariscos. Estos vinos llevan el mismo nombre que la uva que los produce.

En Anjou, es decir la región de Angers, destacan los rosados (de cabernet-sauvignon y groslot), los blancos dulces Coteaux du Layon, los tintos de Saumur Champigny (cabernet franc), los cavas blancos y secos de Saumur (chenin blanc y cabernet).

En Touraine, los vinos más famosos son los tintos de Chinon, Bourgueil, Saint Nicolas de Bourgueil (cabernet franc), los cavas blancos de Vouvray y de Montlouis (chenin blanc únicamente).

Entre los denominados vinos del Centro, sobresalen los blancos secos de Sancerre y el Poully fumé, dos viñedos que se hacen frente a cada lado del Loira (sauvignon blanc). Pero más tierra adentro, los Menetou-Salon, Quincy y Reuilly merecen su reputación (también de sauvignon).

Los vinos del Loira expresan mejor sus calidades cuando se beben jóvenes. Sin embargo, los tintos de Chinon pueden criarse más tiempo.

Los viticultores se reúnen en gremios profesionales, los «Comités Interprofessionnels des Vins de...» que, a diferencia de los «Consejos Reguladores» españoles, no integran a miembros de la Administración. Controlar el cumplimiento de las regulaciones es tarea del «I.N.A.O.» (Institut National des Appellations d'Origine).

Esto por lo que respecta a la parte seria del trabajo de la viña pues, en esta profesión, su gente sabe vivir, reír, beber y comer (bien y mucho). Cada año, el 22 de enero, se celebra la fiesta de San Vicente, su Santo Patrón, en cada pueblo que se dedica a la 
viña y al vino. Se repiten los regocijos, cuando llegan los días buenos, liderados por sus cofradías vinícolas. Muy a menudo, en las antiguas tiendas de vino, los dueños anunciaban en sus carteles juegos de palabras sobre «San Vincenzo», como «Vin sans eau», es decir «Vino sin agua», o «20-100-0» que se pronuncia igual.

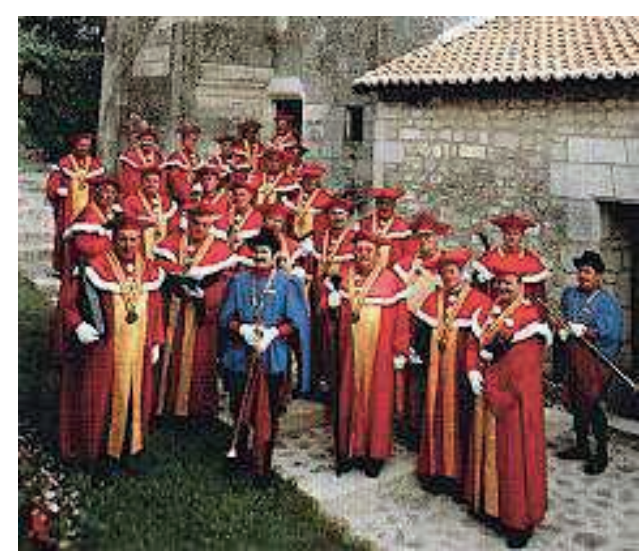

Cofradía «Les Entonneurs rabelaisiens»

\subsection{Origen de la poda (en plan de broma)}

Según dicen los viticultores del Loira, en el año 350, San Martín, futuro obispo de Tours, que ya era un importante terrateniente dueño de viñas en toda la región, fue a visitar y asesorar a los monjes de una abadía, también productores de vino. Ató su burro al extremo de una fila de cepas y se fue a sus menesteres con los religiosos. Al regresar, el animal se había comido cantidad de hojas jóvenes. A la vendimia siguiente, se dieron cuenta de que esas cepas habían producido más y mejor que las otras. No faltaron los monjes en repetir la experiencia, pero mejorando la técnica, por supuesto.

\subsection{Aficionados de los vinos del Loira}

En 1154, Enrique II Plantagenet, Conde de Anjou, nacido en Le Mans, se convirtió en rey de Inglaterra. Ello permitió un desarrollo tremendo del negocio de los vinos de 
Touraine y Anjou con los Ingleses. Además, a la corte también le gustaban los Burdeos, pues Alienor (Leonora), Duquesa de Aquitania, se había casado con Enrique II, convirtiéndose en reina de Inglaterra.

Posteriormente, los ingleses perdieron todos sus territorios en el Oeste y Suroeste de Francia. El negocio del vino se orientó hacia Holanda, con mucho éxito también. Se exportaba utilizando barcos holandeses que venían a cargarlo hasta Tours. Desgraciadamente, ese tráfico cesó durante el reinado de Luis XIV, debido a la guerra contra ese país, en 1672.

Hoy día, los Americanos del Norte, los Británicos y los Belgas son grandes consumidores de vinos del Loira.

En el siglo XVI, el que más fomentó los vinos de Touraine, donde tenía su casa solariega, «La Devinière», fue Rabelais. Este religioso, primero franciscano, luego benedictino (porque la regla era menos rigorosa), médico $y$, sobre todo, humanista, fue un autor humorístico y satírico de primera fila en la literatura francesa. Sus dos primeras obras, Pantagruel (el hijo) y Gargantúa (el padre), cuentan las vidas y las hazañas de estos gigantes, en los entornos de Touraine y de París. Nada más nacer, Gargantúa, en lugar de llorar y mamar, se puso a gritar: "i A beber, a beber!". No hay capítulo en la obra sin alabanza al buen vino, a la «Dive Bouteille» o al placer de beber.

\section{Medio ambiente y centrales nucleares}

El río Loira es el último río salvaje en Europa. Su cauce es libre, sin presas, salvo la de Villerest muy arriba, ni esclusas. Vive al ritmo de la naturaleza. Eso le permite abrigar una gran variedad de humedales, con una fauna y una flora riquísimas. 
Pero en los años 70, debido a la crisis del petróleo, Francia se planteó claramente la orientación de su política energética nuclear. Como las centrales de este tipo necesitan medios para enfriar los reactores, lo más fácil y económico es construirlas en la ribera de un río. El Loira, por supuesto, tiene las suyas, que son cuatro: Belleville entre Cosnes y Gien, Dampierre en Burly entre Gien y Orléans, Saint Laurent des Eaux entre Orléans y Blois, Avoine entre Tours y Saumur. Con las aguas tan bajas que tiene el río en verano, a veces, las centrales no pueden funcionar con toda seguridad, sin un aumento artificial del caudal. Entonces se liberan las aguas de las presas de Villerest $\mathrm{y}$, sobre todo, de Naussac, en el río afluente Allier, especialmente construida para este fin.

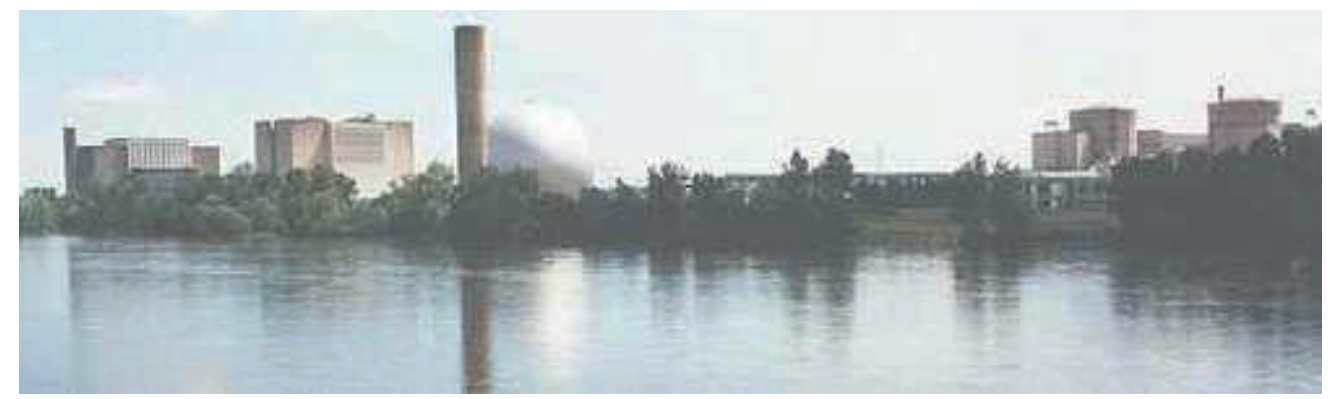

Vista general de la central nuclear de Avoine 


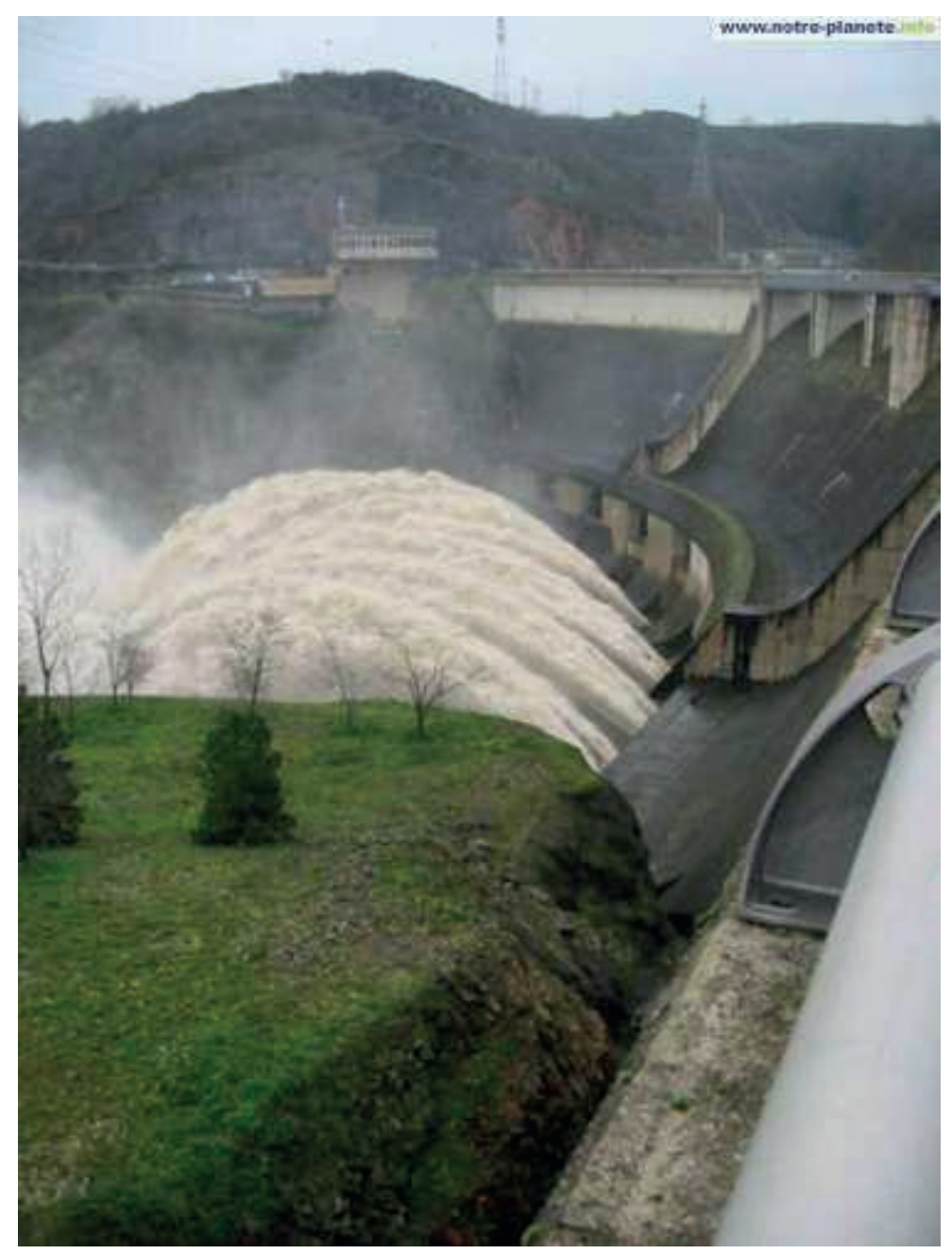

Detalle de la presa de Villerest

\section{Cuando se enfada la Naturaleza}

\subsection{Grandes riadas}

Ya hemos mencionado las extremas variaciones del caudal del río. Desde siempre, los ribereños del Loira han conocido sus tremendas riadas. Son de tres tipos:

- las crecidas con origen en los Cévennes, una sierra del Sur del Macizo Central. Se producen cuando el aire caliente húmedo del Mediterráneo, a veces oriundo del Sahara, choca contra un frente frío en las alturas de los Cévennes. Resultan lluvias torrenciales que provocan inundaciones muy peligrosas en el cauce superior del 
Loira y en el de su primer gran afluente, el Allier, pero que se limitan a esa región montañosa. Así, en septiembre de 1980, en la aldea de Brives-Charensac, el nivel del río pasó de 0,30 m, a las 6 h de la mañana, a 6,70 $\mathrm{m}$ a las $13 \mathrm{~h}$. La riada se cobró la vida de 8 personas y 30 más resultaron heridas.

- las crecidas de tipo oceánico, que ocurren en invierno, cuando llegan las grandes lluvias oriundas del Atlántico. Afectan, sobre todo, a los afluentes del cauce inferior y al río mismo, entre Tours y la desembocadura.

- las grandes inundaciones resultado de la combinación de las dos primeras causas. Afectan a todo el cauce y el río se desborda sobre las llanuras cercanas. Las más terribles ocurrieron en 1846, 1856 y 1866. En junio de 1856, el agua alcanzaba los 2 metros en el centro de Tours. Son muchos los edificios y casas de las ciudades del río que todavía llevan las señales y fechas de los niveles más altos de esas riadas.

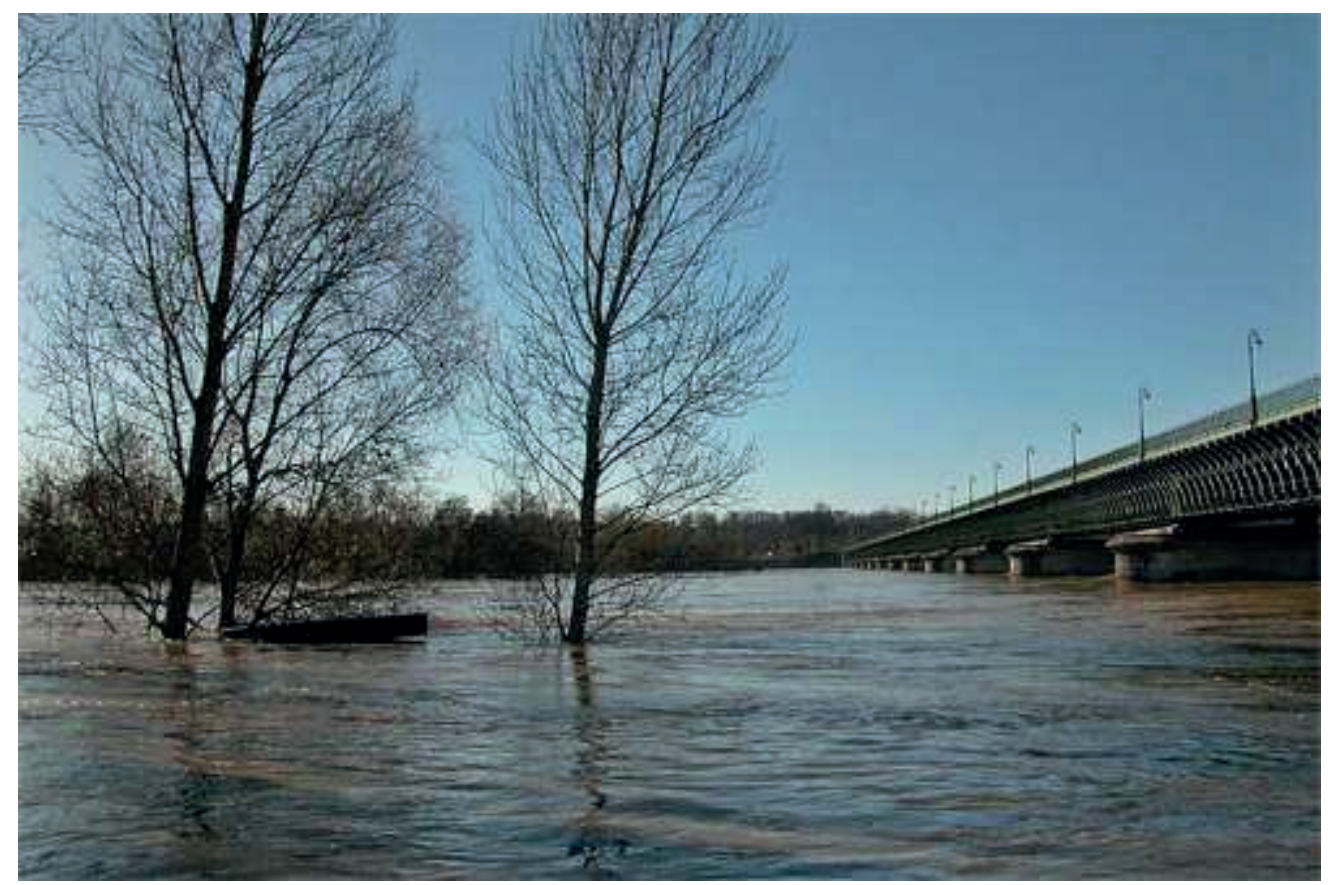

Crecida del Loira a su paso por Briare 


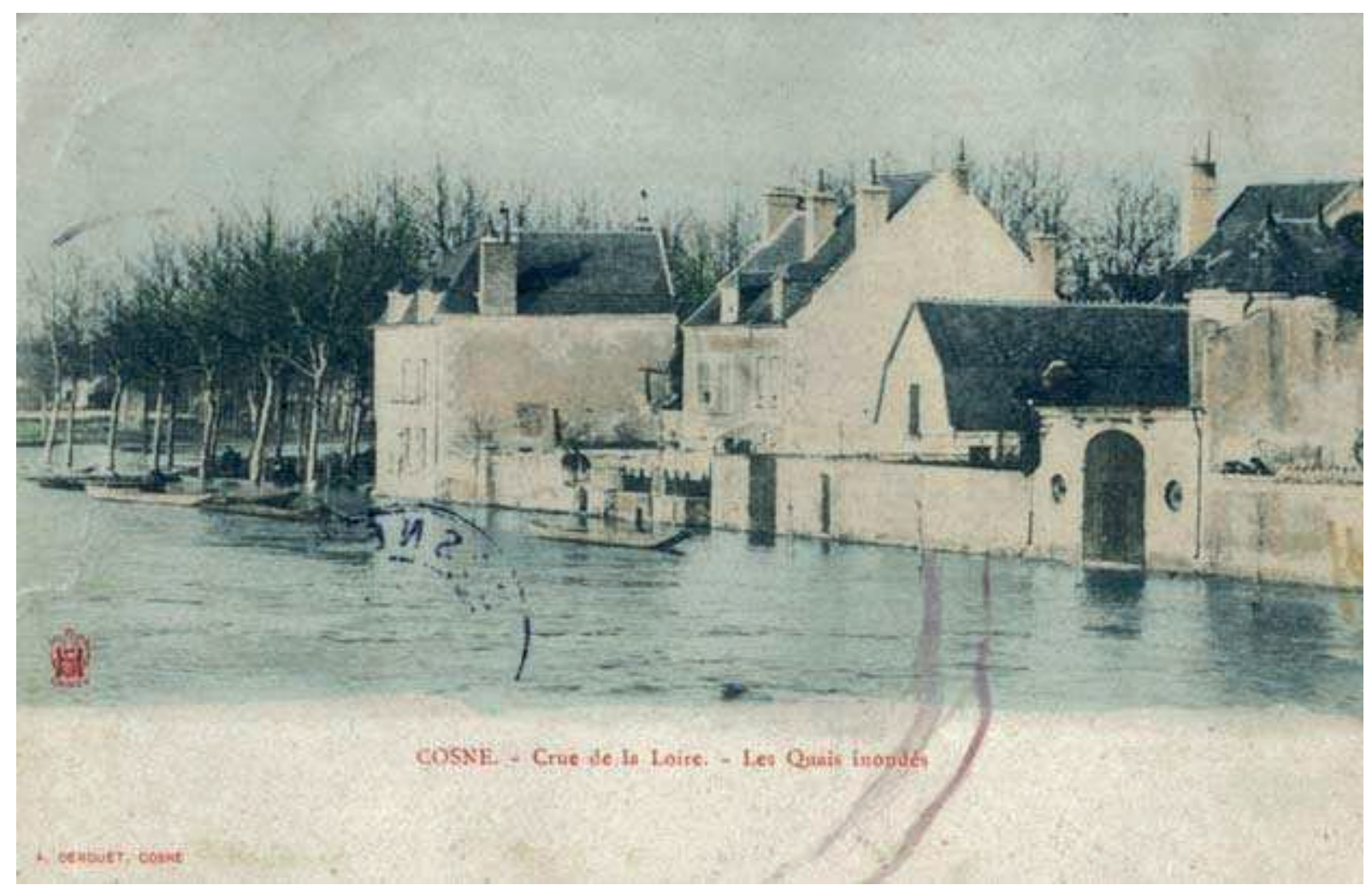

Muelles inundados de la orilla del Loira, en Cosne

Para luchar contra estas catástrofes, la primera medida fue la construcción, a lo largo de los años, de diques de tierra. Los primeros de que tenemos constancia datan de la época de Luis el Piadoso, nieto de Carlomagno. Por esta razón, hoy existen dos muros continuos de cientos de kilómetros de longitud, (les levées) que protegen los campos y las zonas urbanas o industriales a lo largo del río. Algunos tienen dispositivos (déversoirs) para desviar las aguas de la inundación a inmensas zonas sin construcciones, especialmente reservadas para ello. Así se merma la potencia de la riada principal. Además, se ha construido la presa de Villerest, río arriba de Roanne, única solución para oponerse a las riadas en la parte superior del río.

Es cierto que, durante todo el siglo $\mathrm{XX}$, no hubo inundaciones devastadoras, gracias a esas medidas, y también a consecuencia de las continuas extracciones de arena en el 
lecho del río. Eso no significa que la amenaza haya desaparecido, y los expertos siguen vigilando el cauce. La última riada seria ocurrió en el invierno de 2003.

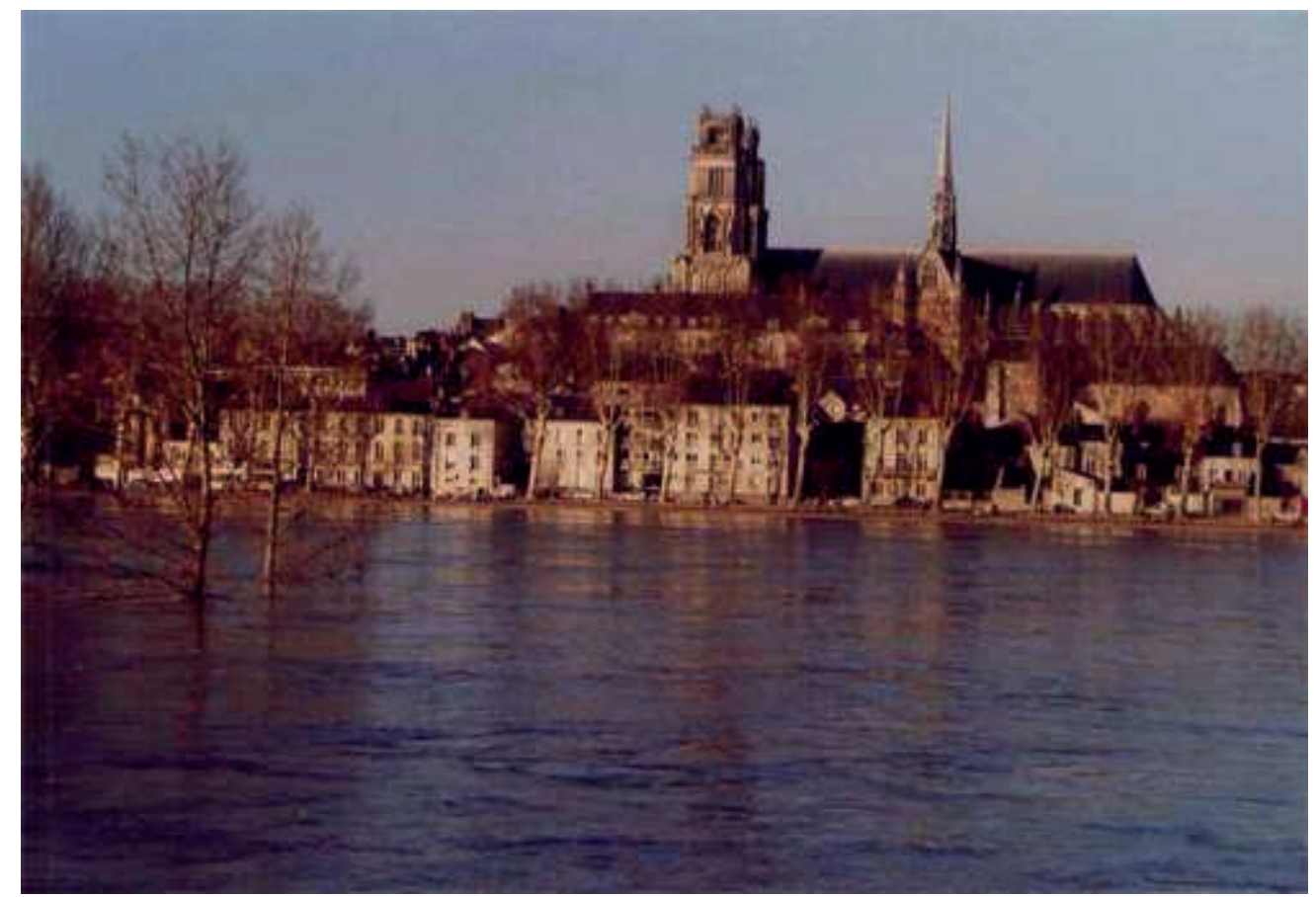

Riada en Orléans. Año 2003

\subsection{El hielo}

Otro capricho de la naturaleza viene con los grandes fríos. Paulatinamente, las aguas se hielan, formando bloques que chocan entre sí hasta soldarse completamente sobre decenas de kilómetros. La última vez ocurrió en enero de 1985. 


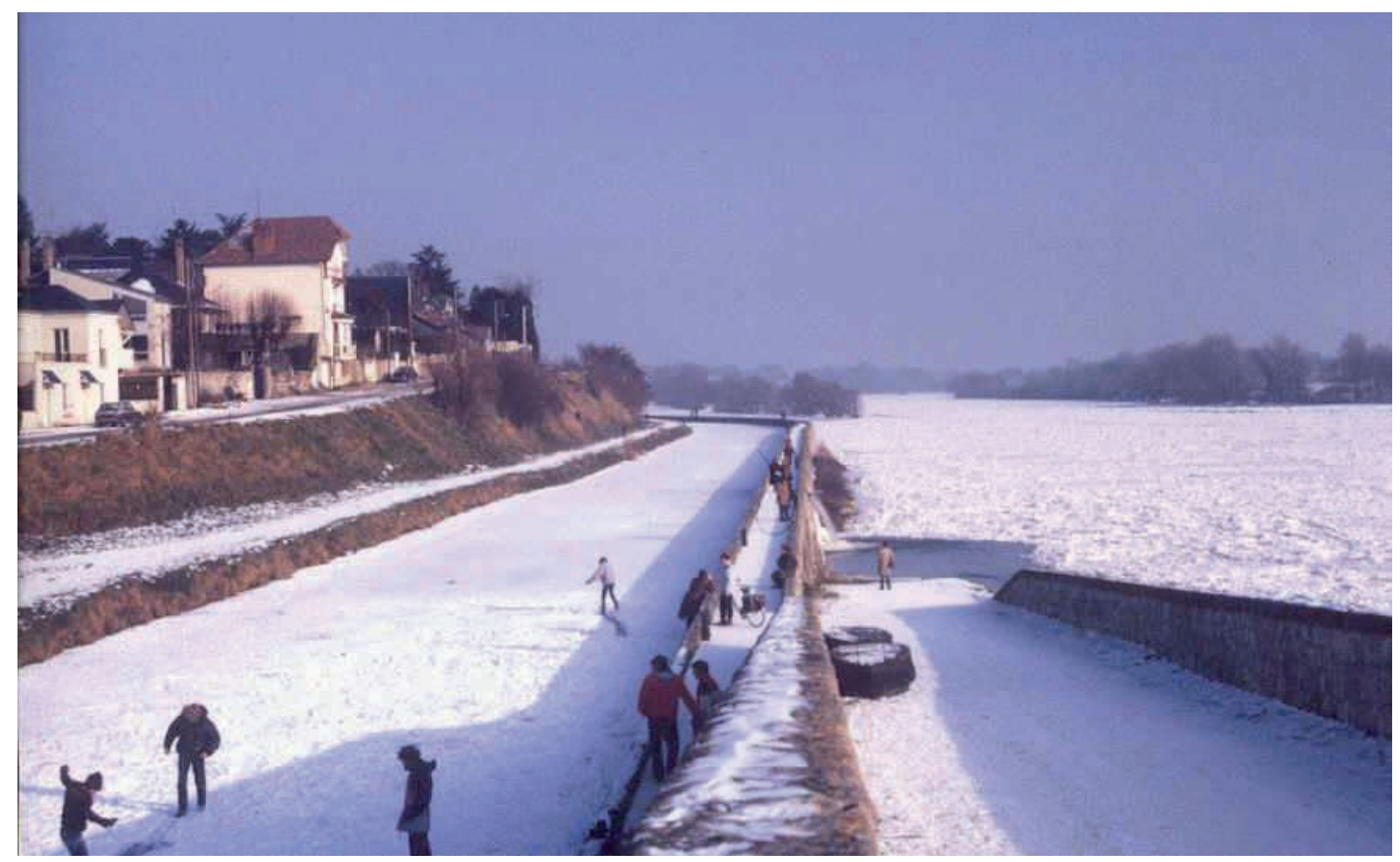

El cauce del Loira totalmente helado

El peligro llega cuando se templa la temperatura y esta inmensa y pesada masa de hielo empieza a moverse río abajo. Los puentes son los que más daños sufren, llegando, en ocasiones, a ser derribados. Es frecuente tener que llamar a los Ingenieros del Ejército para hacer volar el muro de hielo con explosivos. 


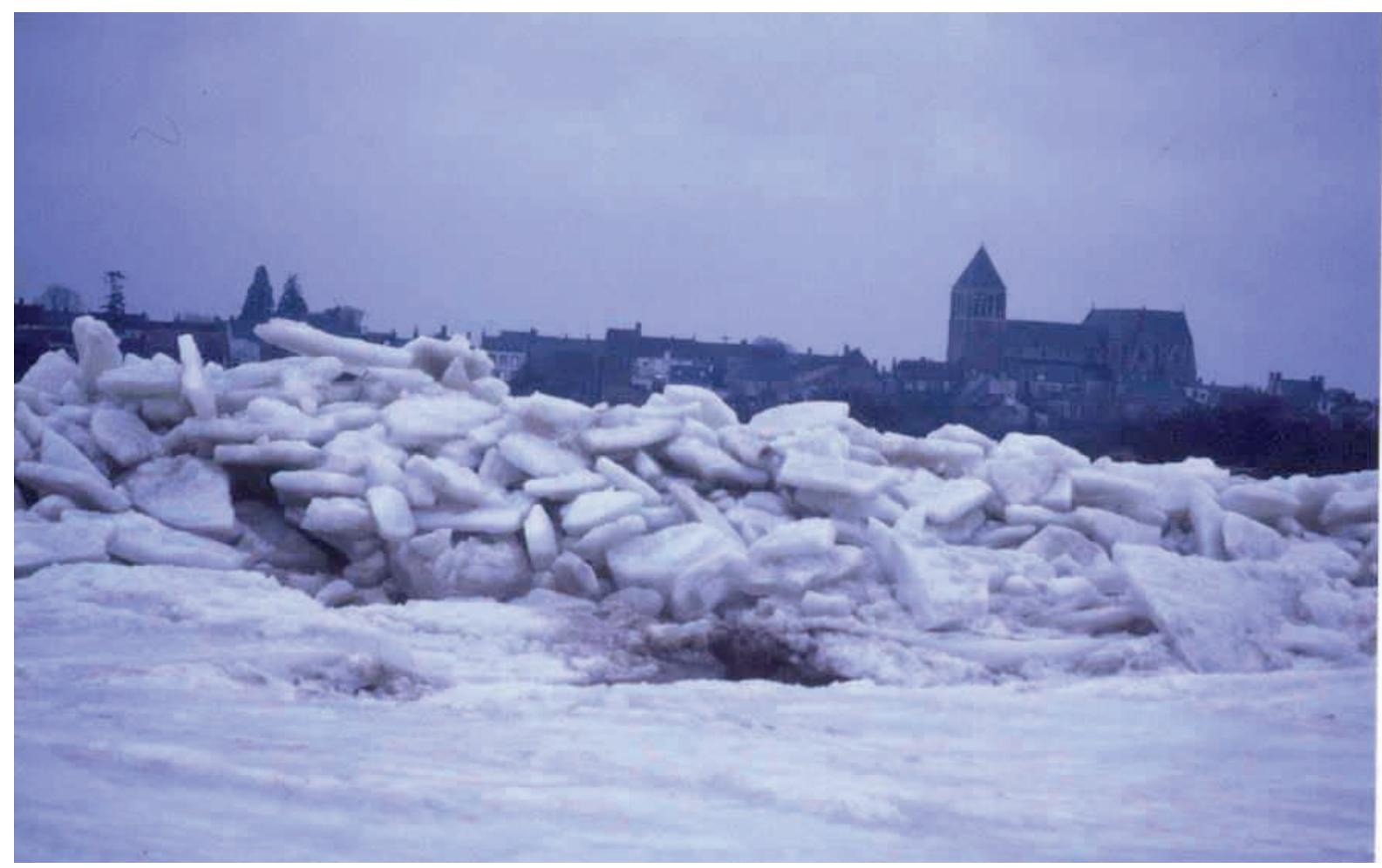

\section{El río Loira helado}

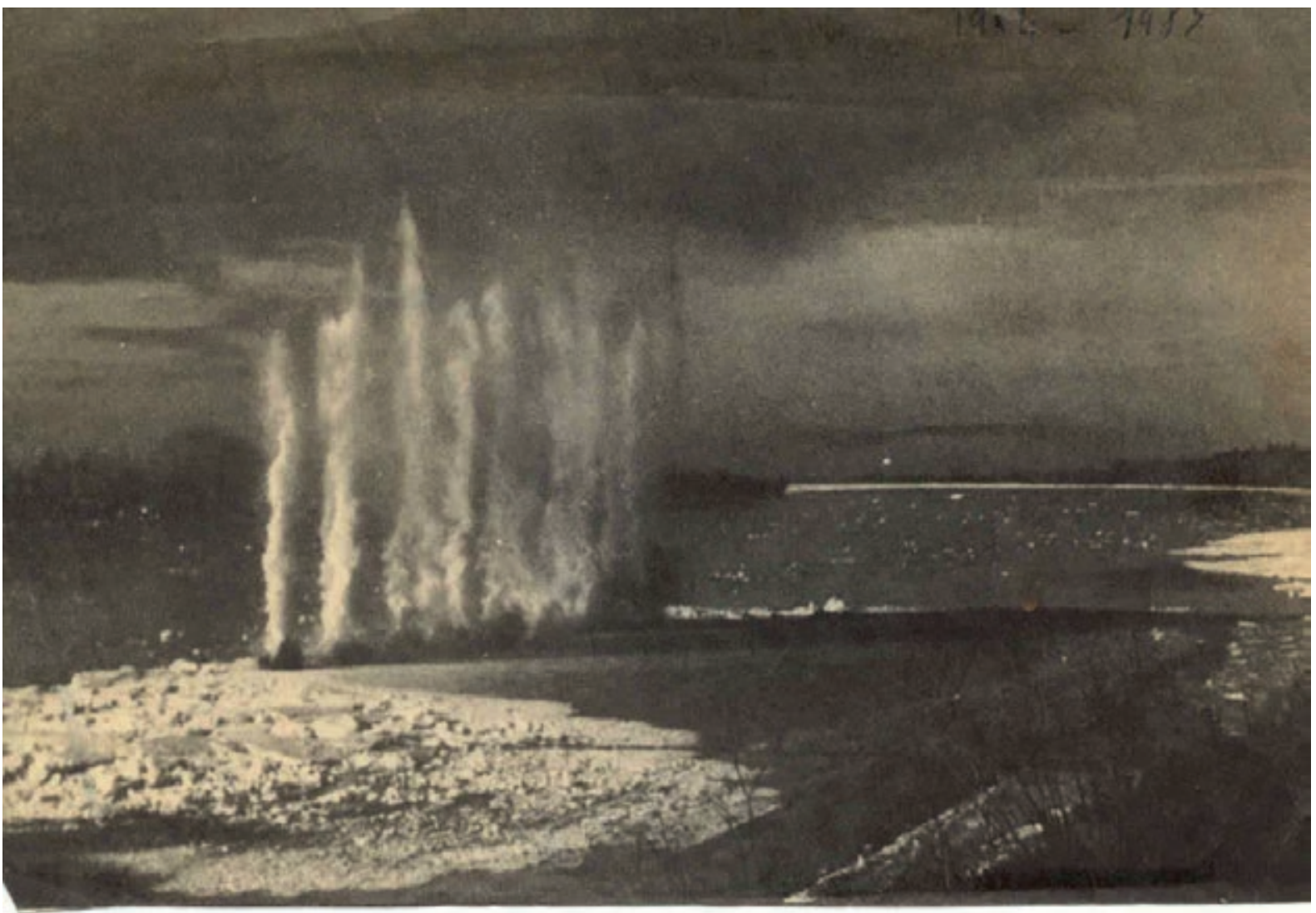

Voladura de la masa de hielo para preservar los puentes 


\section{Conclusión}

A lo largo de los siglos, los hombres han aprovechado la diversidad y la riqueza del río Loira para forjar su propia cultura, la ligeriana: actividades ligadas al río, construcción de maravillas arquitectónicas, cultivo de la vid, protección del medio ambiente, energía nuclear.

A pesar de esas centrales, por fin, en 2000, el jurado de la UNESCO otorgó a la parte del cauce entre Angers y Sully-sur-Loire el título de Patrimonio Mundial de la UNESCO. Su informe rezaba: «el valle presenta un paisaje cultural excepcional de gran belleza, con ciudades y pueblos históricos, grandes monumentos y castillos, tierras cultivadas y moldeadas por siglos de interacción entre las poblaciones y su entorno físico, en particular el río Loira en sí mismo».

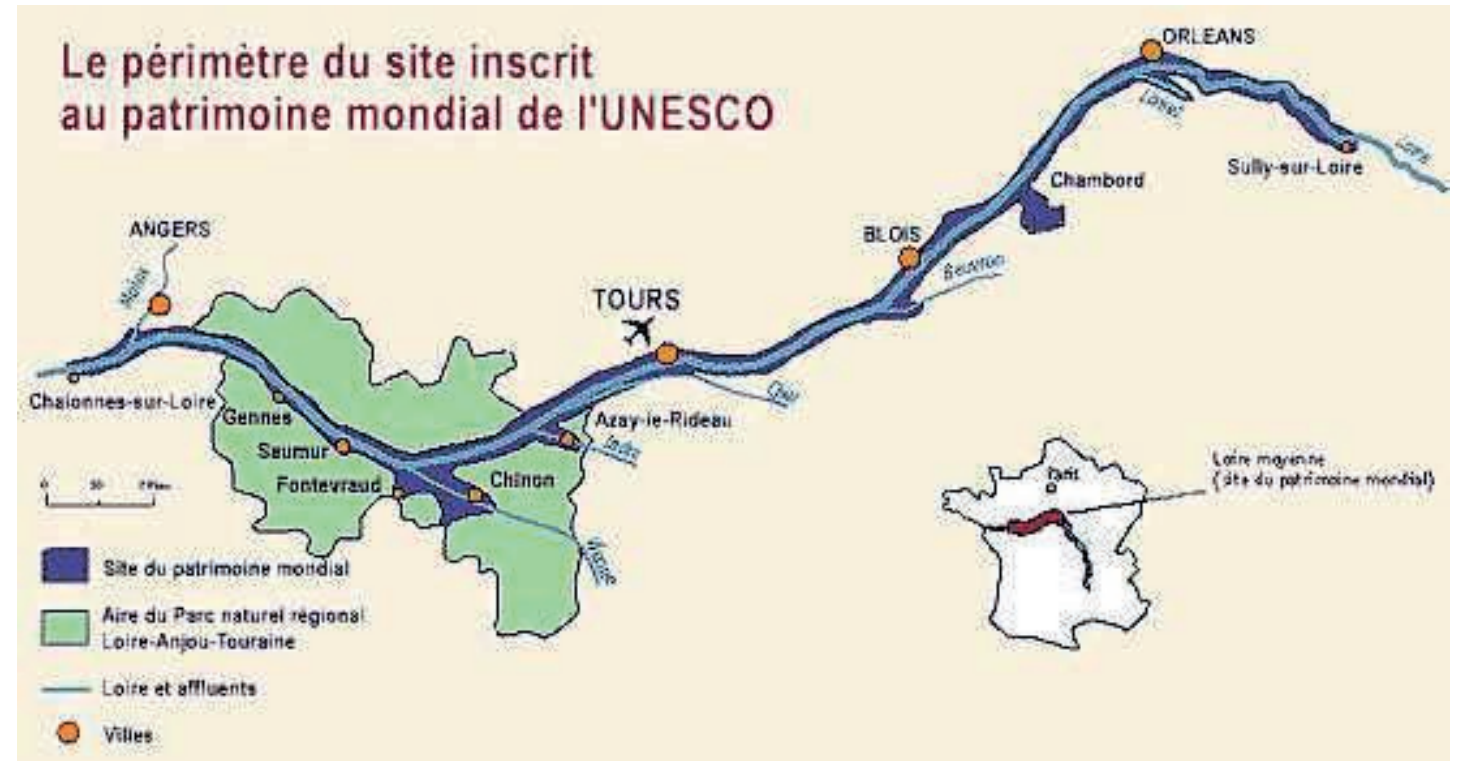

Mapa de la zona declarada patrimonio mundial de la UNESCO (en azul oscuro) Área del Parque Natural Regional Loira-Anjou-Touraine (en verde)

Cauce del río Loira (en azul claro)

Ciudades más importantes (en naranja)

Abajo, a la derecha, situación de la zona en el mapa general de Francia (en rojo oscuro) 